\title{
Immediate effects of manual lymphatic drainage in healthy women
}

\author{
Beatriz Landin Alves ${ }^{1}$, Rogério Eduardo Tacani², Nelson Carvas Júnior ${ }^{1}$, Igor Fagioli Bordello Masson ${ }^{1}$,
} Thiago Saikali Farcic ${ }^{1}$, Aline Fernanda Perez Machado ${ }^{1 *}$.

${ }^{1}$ Universidade Paulista (UNIP), São Paulo (SP), Brazil; ${ }^{2}$ Universidade Cidade de São Paulo (UNICID), São Paulo (SP), Brazil.

\section{ABSTRACT}

Background: Manual lymphatic drainage (MLD) is a technique widely used in clinical practice to favor the absorption and transport of interstitial fluid and macromolecules through the lymphatic system. Usually, MLD is indicated as a way of treating edema and lymphedema of different etiologies. Objective: Analyze the immediate effects of manual lymphatic drainage on the volume and sensation of the lower limbs of healthy women. Methods: The sample consisted of 40 healthy women aged between 18 and 44 years, sedentary and with body mass index between $18,5-29,9 \mathrm{Kg} / \mathrm{m}^{2}$. They were bilaterally submitted to a single MLD session on the lower limbs. The evaluation of the volume of the lower limbs was made by perimetry and the sensation in the lower limbs was determined through a questionnaire prepared by the authors of this study. Results: It was observed that there was no statistically significant difference in the perimetry of the lower limbs $(p \geq 0.05)$, however a decrease was reported in the "sensation of weight" in the lower limbs and in the "tiredness to walk". Conclusion: Manual lymphatic drainage did not decrease the volume, but it did improve the feeling of heaviness and tiredness to walk providing a feeling of lightness in the lower limbs.

Keywords: Edema; Women; Manual Lymphatic Drainage; Physiotherapy Modalities; Aesthetics.

\section{BACKGROUND}

Manual lymphatic drainage (MLD) is a manual technique designed to improve the functions of the lymphatic system by light and smooth, slow and rhythmic maneuvers, which obey the path of the superficial lymphatic system. It is indicated for patients who have different types of circulatory, vascular and lymphatic disorders. Edema is an accumulation of interstitial fluid, which leads to changes in the normal dynamics of capillaries and interferes with the functioning of the pumping mechanism of the lymphatic and venous systems $^{(1,2)}$. Thus, edema is the main symptom treated by MLD for optimizing the functions of the lymphatic system. The formation of edema may be related to the posture adopted for long periods of the day, type of clothing used, climate, physical activity, hormonal fluctuations, salt intake, obesity, age, lifestyle, family history and others ${ }^{(3)}$.

MLD has been used as a way of treating several disorders, such as: cellulite ${ }^{(4-7)}$, localized adiposity $^{(5,7)}$, postoperative of cosmetic plastic surgeries $^{(8)}$, postoperative of orthognathic surgery ${ }^{(9)}$, post-traumatic edema ${ }^{(10,11)}$, lymphedema ${ }^{(12,13)}$, chronic venous insufficiency ${ }^{(14-16)}$, lipedema ${ }^{(17)}$, premenstrual edema $^{(18)}$, gestational edema ${ }^{(19,20)}$ and fibromyalgia ${ }^{(21,22)}$. Especially, women in menacme, suffer the influences of the different phases of the menstrual cycle and, consequently, they are subject to changes caused by the difference in concentration of the female hormones participating in this process ${ }^{(23)}$. The presence of edema can cause discomfort, a feeling of heaviness in the limb, tiredness, decreased functional and professional performance, and can directly interfere with quality of life ${ }^{(3)}$. MLD is a technique widely used in clinical practice as a way to promote overall muscle wellbeing and relaxation. However, the scientific basis for its use in healthy women is still insufficient, not reproducing what occurs in most physiotherapy and aesthetic clinics. Therefore, the aim of this study was to analyze the immediate effects of manual lymphatic drainage on lower limb volume and body satisfaction in healthy women.

\section{METHODS}

\section{Ethical considerations}

This study is a blinded clinical trial, which began after approval by the Research Ethics Committee of the Universidade Paulista (protocol number: 13022019.8.0000.5512). All volunteers agreed and signed the Informed Consent Form.

\section{Sample}

The sample consisted of 40 women, aged between 18 and 44 years, healthy, sedentary and with body mass index (BMI) between 18.5 - 29.9 $\mathrm{Kg} / \mathrm{m} 2$. 
They were invited to participate in the study, constituting a sample for convenience. The exclusion criteria were: postoperative period less than six months, pharmacological or clinical treatment for weight loss, having undergone aesthetic treatment in the last six months, presence of acute infections and inflammations, cardiac patients, pregnant women, puerperal and lactating women, presence of thrombosis deep vein, phlebitis and thrombophlebitis, presence of acute or chronic edema in any part of the body and if the patient had fever or malaise.

\section{Outcomes}

The volunteers were evaluated in two moments, being pre and post-intervention with the MLD technique, by a blind evaluator, who did not know which procedure the volunteer would undergo and remained outside the room during the intervention. A physical therapy evaluation form, proposed by the authors, was used, consisting of identification, anamnesis, physical examination and questionnaire about the sensation in the lower limbs.

On physical examination, an anthropometric assessment was performed, by measuring body mass and height, to obtain BMI. To measure body mass, a digital scale was used with the volunteer wearing swimsuits, and body height was assessed with a stadiometer.

\section{Perimetry}

The volume of the lower limbs was determined by the perimetry performed on the thighs, legs and ankles bilaterally. The thigh and leg perimetry was performed with the volunteer in orthostatism, with measurements every 7 centimeters from the popliteal line, with three levels of thigh (Thigh 1, Thigh 2 and Thigh 3), four levels of leg (Leg 1, Leg 2, Leg 3 and Leg 4) and the ankle perimeter was performed using the Figure Eight method with the volunteer in the supine position, so that the ankle remained in a neutral position24, totaling 8 levels of perimeter.

Questionnaire on the sensation of the lower limbs

The questionnaire about the sensation of the lower limbs was elaborated by the authors of this study based on the reports obtained by the patients in clinical practice. It was composed of four questions, three of which were repeated in the preand post-intervention evaluations, so that the volunteer should explain the sensation of her legs.

Question 1 was: "Explain the sensation of your legs with just one word:", there were no answer options and the volunteer could use any word she thought she would refer to. Questions 2 and 3 were:
"Do you feel your legs are heavy?" and "Due to the weight you feel, are you tired of walking?", respectively, for both the volunteer should answer "yes" or "no", if her answer was "yes", she should score on a Visual Numerical Scale (VNS) from 0 (zero), being "weightless" or "without fatigue", to 10 (ten), "very heavy" or "very tired", respectively.

Question 4 was different in the moments of evaluations, being in the pre-intervention: "How often do you feel your legs tired?", With the following answer options: "never", "often", "sometimes" and "always"; whereas in the post-intervention: "Choose a word that defines the sensation of lower limbs:", with the options: "light", "little lightness", "normal", "heavy" and "other" (the volunteer should say a word to suit your sensation in the lower limbs).

\section{Therapeutic procedure}

The therapeutic procedure consisted of applying a single session of MLD, with an average duration of 40 minutes each. The volunteer was positioned on the stretcher in the supine position, in a symmetrical and comfortable way, wearing bathing suits. Then, it was performed the evacuation of términus (10 times) and diaphragmatic exercises (5 repetitions). The DLM technique used was the Leduc®2 method.

The standardization for the execution of the technique was initiated by the left lower limb followed by the right one, the maneuvers followed the proximal to distal direction and return to the proximal of the limb, in the direction of the lymphatic flow, with slow and rhythmic speed, light and soft pressure, using maneuvers accurate with smooth skin traction.

The application of the technique, in each of the lower limbs, started by evacuating the inguinal lymph nodes (10 times), followed by resorption and uptake maneuvers in the thigh region divided into three parts (5 times in each part), evacuation of the popliteal lymph nodes (10 times), followed by resorption and uptake maneuvers in the leg in three parts (5 times in each part) and in the ankle (supramalleolar, retromalleolar, inframalleolar and instep) and ending with the return of the maneuvers in the reverse sequence.

\section{Statistical analysis}

For statistical analysi it was used the software $\mathrm{R}$ for Mac IOS. The normality of the data was verified using the Shapiro-wilk test. For comparison between the pre and post-intervention values, the paired ttest for VNS was used and for the categorical ones, the Cochran $Q$ test was used for paired nominal data. The significance level of $p \leq 0.05$ was adopted. 


\section{RESULTS}

Of the 57 women who were interested in participating in the research, 6 were above the established age group, 5 practiced physical activities regularly, 3 were in the recent postoperative period, 1 being for abdominoplasty and 2 for sclerotherapy, 2 were undergoing clinical treatment for weight loss, and 1 was breastfeeding. Therefore, the sample consisted of 40 women who received the application of the DLM technique in both lower limbs.

The demographic characteristics of the patients are described in Table 1, whose variables analyzed are expressed in absolute and percentage values (\%). The mean age was 30.13 years $( \pm 9.20)$, the body mass was $67.23 \mathrm{~kg}( \pm$ $11.10)$ and the BMI was $25.36 \mathrm{~kg} / \mathrm{m} 2( \pm 4.03)$. Regarding ethnicity, $72.5 \%$ were white, $22.5 \%$ black and $5 \%$ others. Regarding marital status, $55 \%$ were married and $45 \%$ were single. Most volunteers had never undergone the MLD technique (55\%) and did not use hormonal contraceptives $(52.5 \%)$. As for life habits, $7.5 \%$ of the volunteers were smokers, $80 \%$ did not use alcohol and $52.5 \%$ did not use hormonal contraceptives.

Table 1. Clinical characteristics of patients in the pre-assessment.

\begin{tabular}{lc}
\hline Clinical characteristics & Sample $(\mathrm{n}=40)$ \\
\hline Age (years) & $30,13( \pm 9,20)$ \\
Body mass $(\mathrm{Kg})$ & $67,23( \pm 11,10)$ \\
Body mass index $\left(\mathrm{Kg} / \mathrm{m}^{2}\right)$ & $25,36( \pm 4,03)$ \\
Race $(\%)$ & \\
$\quad$ White & $72,5 \%(\mathrm{n}=29)$ \\
$\quad$ Black & $22,5 \%(\mathrm{n}=9)$ \\
Others & $5 \%(\mathrm{n}=2)$ \\
Marital status $(\%)$ & \\
$\quad$ Married & $55 \%(\mathrm{n}=22)$ \\
$\quad$ Single & $45 \%(\mathrm{n}=18)$ \\
Use of hormonal contraceptives & \\
Yes & $47,5 \%(\mathrm{n}=19)$ \\
No & $52,5 \%(\mathrm{n}=21)$ \\
\end{tabular}

\section{Perimetry}

There was no statistically significant change in all levels of perimetry (thigh, leg and ankle) in the pre and post-intervention (Figure 1).

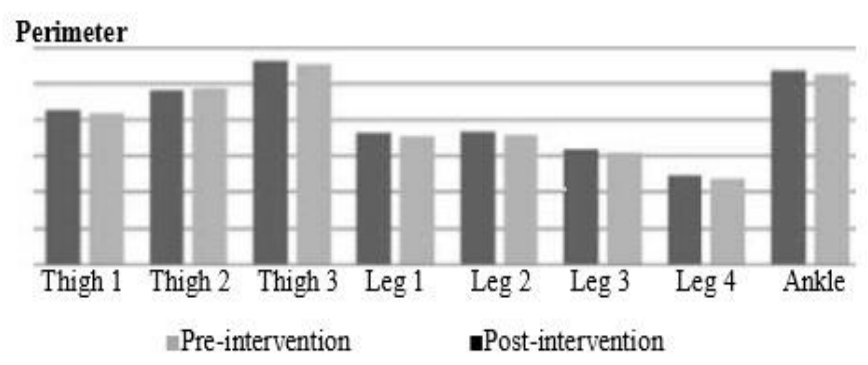

Figure 1. Perimetry of lower limbs

"Note: Thigh $1-7 \mathrm{~cm}$ above the popliteal line; Thigh $2-14 \mathrm{~cm}$ above the popliteal line; Thigh $3-21 \mathrm{~cm}$ above the popliteal line; Leg 1 $7 \mathrm{~cm}$ below the popliteal line; Leg $2-14 \mathrm{~cm}$ below the popliteal line; Leg $3-21 \mathrm{~cm}$ below the popliteal line; Leg $4-28 \mathrm{~cm}$ below the popliteal line; Ankle - perimetry using the Figure Eight Method.

\section{Questionnaire on lower limb sensations}

As for the Questionnaire on the sensations of the lower limbs (Table 2), in Question 1 ("Explain the sensation of your legs with just one word"), the volunteer could use any word that she thought to refer to the sensation of her legs. In the preintervention assessment, the following words were mentioned with their respective frequencies: "tired" (37.5\%, $n=15)$, "normal" $(32.5 \%, n=13)$, "painful" $(10 \%, n=4)$, "Swollen" $(10 \%, n=4)$, "heavy" $(5 \%, n=2)$ and "fatigued" $(2.5 \%, n=1)$. In the post-intervention assessment, "mild" $(47.5 \%, n=19)$, "relaxed" $(25 \%, n=10)$, "well" $(10 \%, n=4)$, "wonderful" $(7.5 \%, n=3)$, "relieved" $(2.5 \%, \mathrm{n}=1)$, "floating" (2.5\%, $\mathrm{n}=1)$ and "comfortable" $(2.5 \%, \mathrm{n}=1)$.

In Question 2 ("Do you feel your legs heavy?"), In the pre-intervention assessment, $62.5 \%(n=25)$ of the volunteers responded that they felt their legs heavy with intensity rated at 6.25 ( \pm 14.81$)$ in the VNS; whereas in the postintervention, there was a statistically significant decrease in the sensation of weight $(2.5 \%, n=1)$ $(p<0.001)$ with a decrease in intensity to $0.05( \pm$ $0.31)$.

In Question 3 ("Due to the weight you feel, are you tired of walking?"), In the pre-intervention, $62.5 \%(n=25)$ of the volunteers answered that they did not feel tired to walk with intensity rated at $2.85( \pm 3.86)$ in the VNS; already in the postintervention, there was a statistically significant decrease in the feeling of tiredness to walk, since $100 \%(n=40)$ reported no as an answer, with intensity classified as $0(p<0.001)$.

And finally, in Question 4 ("How often do you feel your legs tired?"), In the pre-intervention, $47.5 \%(n=19)$ answered "sometimes", $30 \%(n=$ 12) "frequently", $20 \%(n=8)$ "always" and $2.5 \%$ $(\mathrm{n}=1)$ "never". In the post-intervention evaluation, $72.5 \%(n=29)$ chose "light", $25 \%(n=10)$ "little light" and $2.5 \%(n=1)$ "normal". 
Table 2. Questionnaire on the sensations of the lower limbs in the pre and post-intervention evaluations.

\begin{tabular}{|c|c|c|c|c|c|}
\hline \multicolumn{3}{|c|}{ Pre-intervention } & \multicolumn{2}{|c|}{ Post-intervention } & p value \\
\hline \multicolumn{6}{|c|}{ Question 1: "Explain the sensation of your legs with just one word:" } \\
\hline \multirow{7}{*}{ Words } & Tired & $37,5 \%(n=15)$ & Light & $47,5 \%(n=19)$ & -- \\
\hline & Normal & $32,5 \%(n=13)$ & Relaxed & $25 \%(n=10)$ & -- \\
\hline & Sore & $10 \%(n=4)$ & Good & $10 \%(n=4)$ & -- \\
\hline & Swollen & $10 \%(n=4)$ & Wonderful & $7,5 \%(n=3)$ & -- \\
\hline & Heavy & $5 \%(n=2)$ & Relieved & $5 \%(n=2)$ & -- \\
\hline & Fatigued & $2,5 \%(n=1)$ & Floating & $2,5 \%(n=1)$ & -- \\
\hline & Fat & $2,5 \%(n=1)$ & Comfortable & $2,5 \%(n=1)$ & -- \\
\hline
\end{tabular}

Question 2: "Do you feel your legs are heavy?"

$\begin{array}{llll}\text { Yes } & 62,5 \%(n=25) & 2,5 \%(n=1) & \\ \text { No } & 37,5 \%(n=15) & 97,5 \%(n=39) & \\ \text { VNS } & 6,25( \pm 14,81) & 0,05( \pm 0,31) & p<0.001\end{array}$

Question 3: "Due to the weight you feel, are you tired of walking?"

$\begin{array}{llll}\text { Yes } & 37,5 \%(n=15) & 0 \%(n=0) & \\ \text { No } & 62,5 \%(n=25) & 100 \%(n=40) & \\ \text { VNS } & 6,25( \pm 3.86) & 0,0( \pm 0.00) & p<0.001\end{array}$

\section{Question 4:}

Pre-intervention: "How often do you feel your legs tired?"

Post-intervention: "Define the sensation of lower limbs"

\begin{tabular}{llllll}
\multirow{4}{*}{ Words } & Ever & $20 \%(n=8)$ & Light & $72,5 \%(n=29)$ & -- \\
& Often & $30 \%(n=12)$ & Little Lightness & $25 \%(n=10)$ & -- \\
& Sometimes & $47,5 \%(n=19)$ & Normal & $2,5 \%(n=1)$ & -- \\
& Never & $2,5 \%(n=1)$ & -- & & \\
\hline
\end{tabular}

Note: VNS: visual numerical scale.

\section{DISCUSSION}

The results show that the MLD did not change the volume of the lower limbs assessed by the perimetry (thigh 1 , thigh 2 , thigh 3 , leg 1 , leg 2 , leg 3 , leg 4 and ankle). On the other hand, MLD improved the feeling of weight observed by the change of words chosen at different moments of assessment, with $37.5 \%$ in the pre-intervention assessment saying that their legs were "tired" and $32.5 \%$ "normal"; in the post-intervention, $47.5 \%$ reported that their legs were "light" and 25\% "relaxed". In addition, the answers obtained in Questions 1 and 2 show such changes, as MLD was effective in improving the sensation of heavy legs from $37.5 \%$ to $97.5 \%(p<0.001)$, with an intensity of weight sensation of 0.05 in the VNS, and none of the volunteers $(p<0.001)$ reported feeling tired of walking after applying MLD. In the pre-intervention, $97.5 \%$ of the volunteers reported feeling tired in their legs "always", "often" and "sometimes"; in the postintervention assessment, the same volunteers $(97.5 \%)$ reported feeling of "lightness" or "little lightness". The aim of this study was to analyze the immediate effects of MLD on the volume of the lower limbs and the sensation of the lower limbs of healthy women. The initial hypothesis was that the MLD would not provide significant changes in the volume of the lower limbs, as the women who were submitted to the application of this technique were healthy and did not present complaints of edema or any other condition that could interfere with the lymphatic and/or venous circulation of the lower limbs, although they may have a possible subclinical edema related to the weather or the phase of the menstrual cycle ${ }^{(23)}$.

However, it was expected that the volunteers would report changes in the sensation of the lower limbs, due to the physiological and therapeutic effects that MLD promotes, which are evidenced by empirical bases according to the reports of patients in clinical practice. Therefore, the outcomes presented here are in accordance with the initial hypothesis, and the main motivation for carrying out 
this study was to demonstrate that, although MLD does not change the volume of the lower limbs, patients present changes in the weight sensation of the treated region ${ }^{(4)}$, providing scientific basis for the use of the technique in cases of promoting wellbeing and overall body relaxation due to its analgesic effects, muscle relaxation, tension relief and induction of psychological relaxation ${ }^{(25)}$.

Perimetry was performed to check the alteration in the volume of the lower limbs in the thigh, leg and ankle regions after the application of MLD, since this instrument is widely used in clinical practice and scientific studies. To date, no clinical trials have been found to investigate the immediate effect of MLD in healthy women or those with circulatory disorders, which makes it difficult to compare the results obtained here. On the other hand, the conception of this study is highlighted as perspectives and incentives for new scientific research. However, perimetry is a form of classical evaluation, both in clinical practice and in scientific research.

It is important to emphasize that even though the MLD is performed for more sessions, there is no consensus in the literature about its alteration in the perimetry after the application of the technique, being mainly dependent on the presence or not of associated dysfunction. No significant changes were observed after the application of DLM in women with cellulite $\left(10^{4}\right.$ and 14 sessions $\left.^{6}\right)$. There was a decrease in perimetry when MLD was associated with combined therapy (10 sessions) in patients with adiposity located in the abdomen region $^{(5)}$, after 20 sessions of DLM in women with cellulite in the buttocks and thighs ${ }^{(7)}$.

The questionnaire on the sensations of the lower limbs was prepared by the authors of this study due to the lack of validated instruments. The proposal was that there should be simple and objective questions, with answer options to facilitate the tabulation of data and the application of statistical tests and without answer options to allow the volunteers to freely express their sensation in the lower limbs without the influence of standardized responses, since never before has another research on this topic been carried out.

A limitation of this study may be related to some difficulty that the volunteers might have in expressing the sensation of their legs. One way to make the data more objective and quantitative was the use of VNS to quantify the intensity of the referred sensation from 0 (zero) to 10 (ten), zero being no sensation and ten being a lot of sensation, as proposed in previous studies ${ }^{(4,26)}$. The findings of Brandão et al. $(2010)^{(4)}$ corroborate those of the present study, as they did not observe a reduction in the perimetry, but there was an increase in body satisfaction of patients with cellulite who underwent 10 sessions of MLD. The immediate effects of MLD have been studied in recent years ${ }^{(26-29)}$. Ramos et al. $(2015)^{(28)}$ studied the acute responses of the cardiovascular system in healthy women after a single session of MLD. The authors found that there are no major hemodynamic changes in resting heart rate, systolic and diastolic blood pressure before, during and immediately after the MLD session. However, in patients with type 1 diabetes mellitus, a decrease in capillary and urinary glucose was observed as an acute effect after the application of MLD ${ }^{(29)}$. Inoue e Maruoka (2017) $)^{(26)}$ used VNS before and after therapy to assess the degree of physical symptoms, such as fatigue, and a questionnaire identified positive body changes after a single session of MLD: "I feel my body is warmer", "I feel my body is lighter "," I feel it was good for my health".

As future perspectives, it is suggested that volunteers be divided into groups to compare the immediate effects of MLD. It is believed necessary to study the effects of MLD between the different phases of the menstrual cycle ${ }^{(18,23)}$, among women at menacme and after menopause ${ }^{(26)}$ and between users and non-users of hormonal contraceptives, as Camargo et al. (2018) found that after a MLD session there is an increase in natriuresis in nonusers of oral hormonal contraceptives and in users there is an induction to increase the release of glycerol and $\mathrm{ANP}^{(27)}$. In the present study, most volunteers $(52.5 \%)$ used hormonal contraceptives, which may have interfered with the immediate effect of MLD.

It is suggested to carry out more studies on this topic, with a larger sample, using objective and subjective instruments, to identify the sensation of body changes after the application of MLD. Other ways of identifying the volume of the limbs can be used, such as volumetry. It is considered important to clarify the immediate and long-term effects of MLD in order to prove the effectiveness of the technique associated or not with other treatment methods according to the needs of the patients.

\section{CONCLUSION}

Manual lymphatic drainage did not decrease the volume, but it did improve the feeling of heaviness and tiredness to walk providing a feeling of lightness in the lower limbs.

Authors' contributions: BLA and NCJ: Drafting of the article, review and final approval of the article. RTC, IFBM, TSF: Drafting of the article. AFPM: Conception and design of the article, review and final approval of the article. 
Manual lymphatic drainage in healthy women

Financial support: The authors declare that there was no financial support.

Conflict of interest: The authors declare that there was no conflict of interests.

\section{REFERENCES}

1. Tacani R TP. Drenagem linfática manual terapêutica ou estética: existe diferença? Rev Bras Ciênc Saúde. 2008;3(17):71-7.

2. Leduc A LO. Drenagem Linfática - Teoria e Prática. $3^{\mathrm{a}}$ ed2008. $76 \mathrm{p}$.

3. Belczak CEQ GJ, Ramos RN, de Oliveira MA, Belczak SQ, Caffaro RA. Influência do turno laboral na formação de edema dos membros inferiores em indivíduos normais. J Vasc Bras. 2008;7(3):225-30.

4. Brandão DSM dAA, Silva JC, de Oliveira RGCQ, de Araújo RC, Pitangui ACR. Avaliação da técnica de drenagem linfática manual no tratamento do fibro edema geloide em mulheres. ConScientiae Saúde. 2010;9(4):618-24 .

5. Gonçalves CS MJ, da Silva MD. Terapia combinada associada à drenagem linfática reduz lipodistrofia localizada no abdômen de mulheres jovens. Conscientiae saúde (Impr.) 2017;16(2):281-8.

6. Schonvvetter B, Soares JL, Bagatin E. Longitudinal evaluation of manual lymphatic drainage for the treatment of gynoid lipodystrophy. Anais brasileiros de dermatologia. 2014;89(5):712-8.

7. Bayrakci Tunay V, Akbayrak T, Bakar Y, Kayihan $\mathrm{H}$, Ergun N. Effects of mechanical massage, manual lymphatic drainage and connective tissue manipulation techniques on fat mass in women with cellulite. Journal of the European Academy of Dermatology and Venereology: JEADV. 2010;24(2):138-42.

8. Masson IF, de Oliveira BD, Machado AF, Farcic TS, Junior IE, Baldan CS. Manual lymphatic drainage and therapeutic ultrasound in liposuction and lipoabdominoplasty postoperative period. Indian journal of plastic surgery : official publication of the Association of Plastic Surgeons of India. 2014;47(1):70-6.

9. Yaedu RYF, Mello MAB, Tucunduva RA, da Silveira JSZ, Takahashi M, Valente ACB. Postoperative Orthognathic Surgery Edema Assessment With and Without Manual Lymphatic Drainage. The Journal of craniofacial surgery. 2017;28(7):1816-20.

10. Vairo GL, Miller SJ, McBrier NM, Buckley WE. Systematic review of efficacy for manual lymphatic drainage techniques in sports medicine and rehabilitation: an evidencebased practice approach. The Journal of
MTP\&RehabJournal 2020, 18: 771

manual \& manipulative therapy. 2009;17(3):e80-9.

11. Zebrowska A, Trybulski R, Roczniok R, Marcol W. Effect of Physical Methods of Lymphatic Drainage on Postexercise Recovery of Mixed Martial Arts Athletes. Clinical journal of sport medicine: official journal of the Canadian Academy of Sport Medicine. 2019;29(1):49-56.

12. Ezzo J, Manheimer E, McNeely ML, Howell $\mathrm{DM}$, Weiss $\mathrm{R}$, Johansson $\mathrm{KI}$, et al. Manual lymphatic drainage for lymphedema following breast cancer treatment. The Cochrane database of systematic reviews. 2015(5):CD003475.

13. Muller $\mathrm{M}$, Klingberg $\mathrm{K}$, Wertli $\mathrm{MM}$, Carreira $\mathrm{H}$. Manual lymphatic drainage and quality of life in patients with lymphoedema and mixed oedema: a systematic review of randomised controlled trials. Quality of life research: an international journal of quality of life aspects of treatment, care and rehabilitation. 2018;27(6):1403-14.

14. Crisostomo RS, Candeias MS, Armada-daSilva PA. Venous flow during manual lymphatic drainage applied to different regions of the lower extremity in people with and without chronic venous insufficiency: a crosssectional study. Physiotherapy. 2017;103(1):81-9.

15. dos Santos Crisostomo RS, Candeias MS, Ribeiro AM, da Luz Belo Martins C, Armadada-Silva PA. Manual lymphatic drainage in chronic venous disease: a duplex ultrasound study. Phlebology. 2014;29(10):667-76.

16. dos Santos Crisostomo RS, Costa DS, de Luz Belo Martins C, Fernandes TI, Armada-daSilva PA. Influence of manual lymphatic drainage on health-related quality of life and symptoms of chronic venous insufficiency: a randomized controlled trial. Archives of physical medicine and rehabilitation. 2015;96(2):283-91.

17. Wenczl E, Daroczy J. Lipedema, a barely known disease: diagnosis, associated diseases and therapy. Orvosi hetilap. 2008;149(45):2121-7.

18. Ferreira JJ MA, Tacani $R$, Saldanha MES, Tacani PM, Liebano RE. Drenagem linfática manual nos sintomas da síndrome prémenstrual: estudo piloto. Fisioterapia e Pesquisa. 2010;17(1):75-80.

19. Cataldo Oportus S, de Paiva Rodrigues L, Pereira de Godoy JM, Guerreiro Godoy Mde F. Lymph drainage in pregnant women. Nursing research and practice. 2013;2013:364582.

20. Machado AFP PC, Farcic TS, Tacani PM, Tacani RE, Liebano RE. Efeitos da técnica de drenagem linfática manual durante o período 
gestacional: revisão de literatura. Ter Man. 2012;10(48):223-7.

21. Ekici G, Bakar Y, Akbayrak T, Yuksel I. Comparison of manual lymph drainage therapy and connective tissue massage in women with fibromyalgia: a randomized controlled trial. Journal of manipulative and physiological therapeutics. 2009;32(2):127-33.

22. Yuan SL, Matsutani LA, Marques AP. Effectiveness of different styles of massage therapy in fibromyalgia: a systematic review and meta-analysis. Manual therapy. 2015;20(2):257-64.

23. Tacani PM, Ribeiro Dde O, Barros Guimaraes BE, Machado AF, Tacani RE. Characterization of symptoms and edema distribution in premenstrual syndrome. International journal of women's health. 2015;7:297-303.

24. Reis FA RE, de Carvalho PTC, Belchior ACG, Arakaki JC, de Vasconcelos RA. Análise da confiabilidade do método Figura Oito e da volumetria para mensuração do edema de tornozelo. Rev Bras Med Esporte 2004;10(6):468-71.
25. Shim JM, Yeun YR, Kim HY, Kim SJ. Effects of manual lymph drainage for abdomen on the brain activity of subjects with psychological stress. Journal of physical therapy science. 2017;29(3):491-4.

26. Inoue K, Maruoka H. Effects of simplified lymph drainage on the body: in females with menopausal disorder. Journal of physical therapy science. 2017;29(1):115-8.

27. Camargo ÉAM, Borghi F, Souza ALd, Marcorin DM, Rodrigues LdL, Crege DRXdO, et al. Efeito Agudo da Drenagem Linfática Manual sobre a Natriurese e Lipólise de Mulheres Jovens. International Journal of Cardiovascular Sciences. 2018;31(3):274-81.

28. Ramos PS $\mathrm{Cl}$, Rachel MC, Pacca PSP, Ferreira AP, Ricardo DR. Acute cardiovascular responses to a session of Manual Lymphatic Drainage. Fisioter mov. 2015;28(1):41-8.

29. Palazzin EP KN, Schittler RF, Ruaro JA, Fréz $A R$, Marquetti MGK. Efeito da drenagem linfática manual sobre a glicemia e a glicose urinária em pacientes com diabetes mellitus do tipo 1: estudo preliminar. Sci med. 2012;22(2). 